\title{
CLARITY AND PRONUNCIATION OF AB-INITIO AIR TRAFFIC CONTROLLER
}

\author{
Haryani HAMZAH \\ National University of Malaysia, Bangi, Malaysia
}

Received 21 July 2020; accepted 9 February 2021

\begin{abstract}
The increasing number of aircraft flying around the world has led to the requirement for air traffic controllers to improve their communication skills to face high demand traffic in the future. The paper examines the communication errors in the pilot-controller communication of six ab-initio air traffic controllers during simulation training. More than three hours of conversation were collected and analyzed qualitatively using conversational analysis. The transcribed data yielded a total of 62 instances of communication errors. The data revealed that clarity and pronunciation of ab-initio controllers contributed to problematic communication and reduced the efficiency of the air traffic controllers in communicating. In contrast, pronunciation errors rarely diminished comprehension amongst the controllers and pilots who share a similar first language and are familiar with the use of English in a lingua franca setting. The study also describes other instances of communication errors in pilot-controller communication. The results indicate that ab-initio air traffic controllers need to be proficient in three main areas in pilot controller communication to improve their performance: aviation phraseology, aviation English, and aviation knowledge. The findings suggest that pilots and air traffic controllers should achieve level 4 (operational) in aviation language proficiency test, before proceeding to aviation training that requires them to be proficient in their language skills.
\end{abstract}

Keywords: aviation English, pilot-controller communication, English for specific purposes, non-native speakers, miscommunication, language training.

\section{Introduction}

English has been used globally in the aviation industry since the 1920s and it has inevitably become the lingua franca. With the rapid expansion of the aviation industry across the world, the Federal Aviation Administration [FAA] mandated that every pilot and controller should be proficient in reading, writing, and conversing in English. Subsequently, the International Civil Aviation Organization [ICAO] added that pilots and air traffic controllers are expected to demonstrate their knowledge in the English language and should possess the ability to speak without an accent or impediment which would adversely affect radio communication.

Jones (2003) highlighted that the main factor that causes incidents and accidents to occur is the error in communication between air traffic controllers and pilots or among the flight crew. In 2003, ICAO implemented the Language Proficiency Requirement (LPR) for licensed non-native speaker pilots and air traffic controllers worldwide, who are required to achieve minimum level 4 (operational) or higher. This decision was an immediate response to fatal accidents that occurred due to inadequate English language competency amongst non-native speakers. Furthermore, communication problems in aviation radiotelephony can be described as a two-way outcome, where pilots may encounter difficulty to fully understand the instructions given by the air traffic controllers and vice versa.

English language proficiency is crucial for air traffic controllers to be able to understand and react immediately with the rapidly changing traffic that demands high concentration and comprehension (Trippe, 2019). However, the clarity of instructions given by non-native air traffic controllers often become a significant problem for the pilots to comprehend the instruction or information effectively. As a consequence, this circumstance will reduce the efficiency of communication. Moreover, the differences in pronunciation of the standard phraseology and the variation of English spoken by air traffic controllers may cause ambiguity that will increase the probability of miscommunication in pilot-controller communication.

*Corresponding author. E-mail: yanihamzah@gmail.com 


\section{Background}

Aviation language is justified to be precise, accurate and clear (Barshi, 1997; Mitsutomi \& O’Brien, 2003). Air traffic controllers and pilots are required to communicate with clarity to avoid uncertainty in conversations. Hazrati (2015) and Hamzah and Wong (2018) recommend for air traffic controllers and pilots from different lingua franca to accommodate each other to improve their understanding. Campbell-Laird (2004) postulates that aviation language depends significantly on the context and shared phraseology, which contrasts from general or conversational English. Aviation English is often disjunctive and abbreviated, which is guided with a standard protocol and procedure, while the communication follows the standard phraseology authorized by the ICAO. Although the flow of conversation in aviation communication is predictable for both pilots and air traffic controllers, there are always internal or external factors that require the communication to deviate from a standard conversation. Therefore, pilots and controllers must improvise and converse beyond the standard phraseologies (Tajima, 2004).

In the event of unprecedented situations, the probability for the pilot and controller to use non-standard or beyond standard phraseology is high. Thus, the choice of word, clarity, and pronunciation of the spoken words should be appropriate, concise, and precise for the situation. Currently, many pilots and controllers operating around the world comprise of non-native speakers rather than native speakers (Borowska, 2018). As a result, it should become a custom for both pilots and air traffic controllers to consider (1) the level of language proficiency of the other participants, and (2) level of complexity of the instruction or request given. The linguistic competency of native speakers and non-native speakers plays a significant role in pilot-controller communication. Earlier research done by Howarth (1998) showed that phraseologists agreed that the linguistic competence of a native speaker has an enormous and significant phraseology component. This can be seen through non-standard communication in pilot-controller conversation, whereby native speakers tend to have a better arrangement of competency with correct pronunciation compared to non-native speakers, as non-native speakers often struggle to arrange their sentences and face difficulty in pronunciation. However, from an operational perspective, miscommunication in pilot-controller communication can occur for both native English speakers and non-native English speakers (Kim \& Elder, 2009; Douglas, 2014). Non-native English speakers, however, work twice as hard to improve their proficiency as aviation English demands them to be able to think and speak with an appropriate speed to accommodate highdensity traffic conditions. Estival and Molesworth (2012) suggested that communicating via the radio in general aviation is even more challenging for non-native speakers of English, who needs to be proficient not only at a second language but also in the language of aviation English to communicate.

\section{Pronunciation and clarity in aviation language}

Cardosi et al. (1998) proposed ways to reduce the communication errors between pilots and controllers. They suggested that the controllers should be encouraged to speak slowly and clearly. In their study, they discovered that pilots are more likely to make errors in their read-back when controllers gave complex instructions in a rapid speaking voice. The study also reveals that the complexity of the instruction has a direct impact on the pilot's ability to complete their read-back successfully. Pilots tend to give correct read-back to a less complex instruction given by the air traffic controller. Estival and Molesworth (2012) stated that the miscommunication due to phonology and pronunciation leads to incongruity between the message intended by the speaker, and what has been interpreted by the hearer. Consequently, miscommunication in the pilotcontroller communication will occur. For instance:

ATC instruction to a pilot:

1. Pass to the left of the tower;

2. Pass to the west of the tower.

In the above instruction, the pilot could have misheard the instruction in (1) as (2), which means two different sides of the tower.

Though pilot-controller communication is mostly predictable, Barshi (1997) believed that non-routine communication increases the controllers' workload and will reduce their efficiency in completing a task. Past studies have focused on a specific event of communication and accident or incident reports, rather than routine communication (Drury \& Ma, 2002; Tajima, 2004; Boschen \& Jones 2004; Cookson, 2009). Actual communications will have numerous unpredicted instructions and errors that may be resolved by controllers and pilots before any fatal incident occurs (Morrow et al., 1993; Kim \& Elder, 2009; Molesworth \& Estival, 2015). Even though customary repair strategies and corrections have been practiced globally, no right approach to this problem has yet been established. A necessary measure should be taken to improve radiotelephony communications and investigate the root of the problem.

It is undeniable that human error will always be the most significant factor that needs to be taken into consideration in aviation communication. Research regarding the inaccuracies of the message from both controllers and pilots have been conducted by Barshi and Farris (2013) and Hamzah and Wong (2018). These studies indicate that inaccuracies and vague instructions often occur from multiple causes, which is not due to the message length and complexity given by the controllers only. The task factor is also rated as one of the factors that contribute to the error in "read-back" or "no read-back". In this situation, the controller needs to listen and repair the error by stressing on the correct instruction. ICAO recommends that every air traffic controller and pilot should possess proficient language ability, in addition to being well-versed with standard aviation phraseology. 


\section{Aviation English test}

The Aviation English language test is conducted with the main purpose of discovering the problems and challenges that exist in pilot-controller communication. Mitsutomi and O'Brien (2003) believe that it is now common knowledge that pilots and air traffic controllers must be communicatively competent in English as a language and not be well-versed in only the specialized jargon used in pilotcontroller communications. This awareness has initiated an urgent need for English language proficiency standards to be established both locally and globally. Pilots and controllers must be proficient in the English language, especially those who are non-native speakers.

The test consists of six areas of language use: pronunciation, structure, vocabulary, fluency, comprehension, and interactions. A survey on aviation tests was conducted to determine the requirement of the language proficiency and the type of language test validation available in aviation English. As stated by Alderson (2010), all the tests that were conducted in the aviation context had failed to meet the minimal standards of quality of aviation English language proficiency. He further concluded that the significance of insufficient language tests being made available for pilots, air traffic controllers and other aviation personnel are almost too terrifying to contemplate. It is also a massively disconcerting revelation that until today, ICAO has not chosen to approve or disapprove any test related to aviation English. Furthermore, ICAO is responsible to adhere to the standard of English proficiency of an organization that is involved in language testing for aviation. Aviation English tests should be conducted by one designated organization that can ensure the standard of test is reliable, respectable, and conducted by qualified testers.

\section{The present study}

Early research in aviation communication have concentrated on equipment error and maintenance problems due to language barriers amongst non-native speakers and their respective countries. Since ICAO implemented English language proficiency tests, there is a significant increase in research regarding pilot and controller communication and language testing. However, studies focusing on air traffic controllers' linguistic perspective in aviation communication is inadequate. Hence, the aim of this study is to examine if the clarity and pronunciation of aviation English influence the controller's efficiency to complete their task. Apart from that, additionally, the intends of the study is to investigate other factors that could cause communication error in pilot-controller communication.

\section{Methodology}

This research is qualitative based. It is conducted based on the audio data obtained from the Malaysia Aviation Academy (hereafter "MAVA") aerodrome control simulator training from February 2014 until May 2014. The study is focused on the clarity and pronunciation of ab-initio air traffic controllers in Malaysia. Since the researcher is familiar with the content and procedure of the simulation due to her work experience as an air traffic controller, she was able to transcribe the audio data systematically to fulfil the objective of this study.

Once all the simulations were completed, interviews were conducted to avoid any trepidation on the participants. There were six samples of audio recording and approximately 35 minutes for each session. To avoid any violation of confidentiality, the instructors and ab-initio controllers remained anonymous. The audio recordings were labelled as Controller A, Controller B, Controller C, Controller D, and Controller F. The interviews were conducted with the instructors at a different time and places due to time constraints. The interviews were recorded and manually transcribed and analyzed. Both interviews were labelled as Alpha and Bravo, respectively. Since the interviews were only used as a reference to audio data, it was not necessary to include them in this report.

All ab-initio air traffic controllers have undergone the compulsory courses and training conducted by MAVA and were given an identical exercise to evaluate their competency. The controllers have similar educational backgrounds and a comparatively similar level of English proficiency. They had been introduced and exposed to the same aviation knowledge, and all of them were unfamiliar with aviation practice and terminology before entering MAVA. The instructors comprised of experienced and competent air traffic controllers that have been appointed by the Department of Civil Aviation Malaysia (now Civil Aviation Authority Malaysia).

\section{Data analysis}

The data analysis began by identifying instances of error in audio recording. Table 1 categorizes the types of errors that were identified. The table explains the type of errors from the audio recording. All the errors were counted manually, and the frequency was sorted accordingly. The secondary data was obtained via an interview with the instructor to identify the types of errors and to confirm the correct instructions or transmission that are appropriate for the communication problem. The findings were categorized into four categories adapted from past research findings (BurkiCohen, 1995; Jenkins, 2000; Howard, 2008; Molesworth \& Estival, 2015). The table explains the errors along with an example for each communication error, which represents the conceptual framework for this study.

\section{Findings and discussion}

In this section, the frequency distribution is discussed initially, followed by the types of errors that occur in pilotcontroller communication. The communication problems were categorized into four categories, which have been tabulated in the data analysis. All errors that are significant in this study were extracted and categorized appropriately. 
Table 1. Types of error in pilot-controller communication

\begin{tabular}{|c|c|c|}
\hline Type of error & Explanation and Example & Study \\
\hline Inaccurate Read-back & $\begin{array}{l}\text { Pilot read-back instruction given by the controller } \\
\text { incorrectly, it can be partially incorrect or only a specific } \\
\text { part of the transmission. } \\
\text { Example: Inaccurate read-back of flight level. } \\
\text { Controller: Express } 762 \text { cleared Bangkok via A464 flight } \\
\text { level } 350 \text { squawk } 1223 \text {. } \\
\text { Pilot: Cleared Bangkok via A464 flight level } 330 \text { squawk } \\
1223 \text {. }\end{array}$ & $\begin{array}{l}\text { (Burki-Cohen, 1995; Howard, 2008; } \\
\text { Molesworth \& Estival, 2015) }\end{array}$ \\
\hline Failure to Read-back & $\begin{array}{l}\text { Pilot failed to reply to the controller transmission or } \\
\text { instruction. } \\
\text { Example: Failure to read-back by pilot. } \\
\text { Controller: Asian Express 5724, I have you in sight, } \\
\text { descend 2,000 reports downwind at maintaining level. } \\
\text { Pilot: - }\end{array}$ & $\begin{array}{l}\text { (Burki-Cohen, 1995; Howard, 2008; } \\
\text { Molesworth \& Estival, 2015) }\end{array}$ \\
\hline $\begin{array}{l}\text { Vague / Wrong } \\
\text { Instructions or Request }\end{array}$ & $\begin{array}{l}\text { Controller gives an ambiguous instruction to an aircraft, } \\
\text { which the pilot failed to understand clearly. Unclear } \\
\text { instruction or inaccurate information made by the } \\
\text { controller. } \\
\text { Example: Vague / Wrong instructions or request. } \\
\text { (either runway } 26 \text { or runway } 27 \text {, no correction done by } \\
\text { pilot or controller). } \\
\text { Pilot: Pol } 17 \text { inbound runway } 27 \text {. } \\
\text { Controller: Pol } 17 \text { report short final. } \\
\text { Pilot: Pol } 17 \text { two miles final runway } 26 \text { runway } 27 \text {. }\end{array}$ & $\begin{array}{l}\text { (Burki-Cohen, 1995; Howard, 2008; } \\
\text { Molesworth \& Estival, 2015) }\end{array}$ \\
\hline $\begin{array}{l}\text { Pronunciation or } \\
\text { Clarity }\end{array}$ & $\begin{array}{l}\text { Communication that contains pronunciation error made by } \\
\text { the controller. For this study, pronunciation error could be } \\
\text { an error that cannot be fully understood by the pilot, or an } \\
\text { error in pronunciation that can be understood by the pilot } \\
\text { since there is familiarity between pilot and controller but } \\
\text { cannot be understood by others. } \\
\text { Example: Pronunciation error (base sound like west). } \\
\text { Controller: Indian } 433 \text { join long final report (base). } \\
\text { Pilot: Say again report? }\end{array}$ & (Jenkin, 2000) \\
\hline
\end{tabular}

\subsection{Overall frequency of errors in pilot-controller communication}

Table 2 presents the four categories that have been identified for this study. There were a total of 62 errors recorded with combination from six ab-initio controllers. The highest error was caused due to the vague or wrong information with $34 \%(n=21)$, while $31 \%(n=19)$ of the errors were due to pronunciation, followed by $24 \%(n=15)$ of the error due to incorrect read-back, and $11 \%(n=7)$ of the error due to failure to read-back.

Table 2. Frequency distribution of error

\begin{tabular}{|c|l|c|c|}
\hline Rank & \multicolumn{1}{|c|}{ Type of error } & Total & Percentage \\
\hline 1. & Vague / Wrong instructions & 21 & 34 \\
\hline 2. & Pronunciation error & 19 & 31 \\
\hline 3. & Incorrect read-back & 15 & 24 \\
\hline 4. & Failure to read-back & 7 & 11 \\
\hline \multicolumn{2}{r|r}{ Total } & 62 & 100 \\
\hline
\end{tabular}

\subsection{Frequency errors distribution for ab-initio controllers}

As mentioned before, the participants comprise of nonnative speakers with similar language competency and the same level of education. Table 3 shows that although participants came from a similar background and have completed the same course at MAVA, they face different types of difficulties during the simulation. A total of $26 \%(n=16)$ of errors came from Controller A, who recorded multiple errors in every category, followed by Controller C, Controller E and Controller F at 19\% $(n=12)$. Meanwhile, both Controller B and Controller D recorded the least errors in simulator exercise at $8 \%(n=5)$. Controller $\mathrm{E}$ had the most pronunciation errors. Despite having a different performance in the simulator exercise, all controllers completed their simulator session roughly at the same duration of time.

Although the simulator exercise may have been slightly different from the actual communication, the simulator training demonstrates changes in traffic flow from low traffic sequence which gradually shifted to high traffic sequence. As a result, controllers have to adapt to rapidly 
Table 3. Frequency distribution of errors for ab-initio controller

\begin{tabular}{|c|c|c|c|c|c|c|c|}
\hline Controller & $\begin{array}{l}\text { Incorrect } \\
\text { read-back }\end{array}$ & $\begin{array}{l}\text { Failure to read- } \\
\text { back }\end{array}$ & $\begin{array}{c}\text { Vague } \\
\text { instructions }\end{array}$ & $\begin{array}{l}\text { Pronunciation } \\
\text { error }\end{array}$ & Total & Percentage & Time, min \\
\hline Controller A & 4 & 2 & 5 & 5 & 16 & 26 & 30 \\
\hline Controller B & 2 & 0 & 3 & 0 & 5 & 8 & 35 \\
\hline Controller C & 2 & 3 & 4 & 3 & 12 & 19 & 32 \\
\hline Controller D & 1 & 1 & 2 & 1 & 5 & 8 & 34 \\
\hline Controller E & 2 & 0 & 3 & 7 & 12 & 19 & 30 \\
\hline Controller F & 4 & 1 & 4 & 3 & 12 & 19 & 30 \\
\hline \multicolumn{5}{|l|}{ Sum } & 62 & 100 & 191 \\
\hline
\end{tabular}

changing traffic and use the correct instructions to regulate traffic successfully and safely. At this stage (final simulator exercise), it is important for them to be precise and anticipate all the possibilities that can occur during the simulation. The emergency exercise inserted by instructors is crucial to measure the controllers' competency. The decisions that were made during critical situations give the instructors a glimpse of the controller's critical thinking. As expected, most of the errors made by the controllers take place during high-density traffic and emergencies.

The findings suggest the controller knowledge in aviation phraseology, aviation language, and aviation knowledge influence the efficiency of the controller. Ab-initio controllers naturally lack experience and aviation knowledge. As a result, many face difficulties in forming complex instructions, especially when encountering unprecedented situations. Controllers with less proficiency in fundamental English language will take a longer time to react, and their instructions frequently become incomplete and vague to the hearer. Pilots will eventually request a repetition of the instructions, which increases the perturn in communication. In pilot-controller communication, air traffic controllers inevitably assume the role of the interlocutor, which requires intense and demanding radio practice compared to pilots. As a result, they will use lengthy and compact sentences with a faster speaking rate to accommodate heavy traffic sequences. Pilots, however, are susceptible to make mistakes and give inaccurate readback due to the length of the instructions and their lack of understanding (Barshi \& Farris, 2013).

The result indicates that ab-initio controllers can improve their efficiency by adhering to standard phraseology and avoiding vague and incomplete instructions. Furthermore, they should improve their language ability and be extra attentive whilst handling heavy traffic. Controller B exhibited a higher English language proficiency and spoke clearly with no pronunciation error. Thus, the traffic operated smoothly with fewer hitches and repetition required by both pilot and controller.

\subsection{Controller pronunciation problem}

This section discusses the pronunciation errors in pilotcontroller communication for ab-initio air traffic control- lers by comparing instances of pronunciation error and incorrect read-back to investigate whether pronunciation hinders the understanding of the instruction delivered by controllers.

Pronunciation in aviation English is a consequential skill for pilots and controllers. Every uttered word needs to be clear, concise, and articulate. ICAO defines level 4 (operational) pronunciation as pronunciation, stress, rhythm, and intonation, which are influenced by the first language or regional variation, but only a few interfere with the case of understanding.

In Figure 1, Controller E has the most pronunciation errors at seven with two incorrect read-back, while Controller $\mathrm{B}$ has zero pronunciation error with two incorrect read-back. Controller A has almost the same ratio of errors; five pronunciation errors with four incorrect readback. The findings highlight the two main pronunciation problems that exist among the ab-initio controllers.

Most of the controllers face difficulty in pronouncing common English words rather than aviation-related words, which indicates that although aviation English contains lots of jargon and abbreviations, ab-initio controllers can pronounce them correctly. However, the result stipulates that controllers may be lacking in fundamental English proficiency, as suggested by Tajima (2004). Other evidence was seen during the exercise, where controllers performed respectably during light traffic sequences. However, as the traffic became heavier and more congested, the patterns of the controllers' speech became irregular and stuttered.

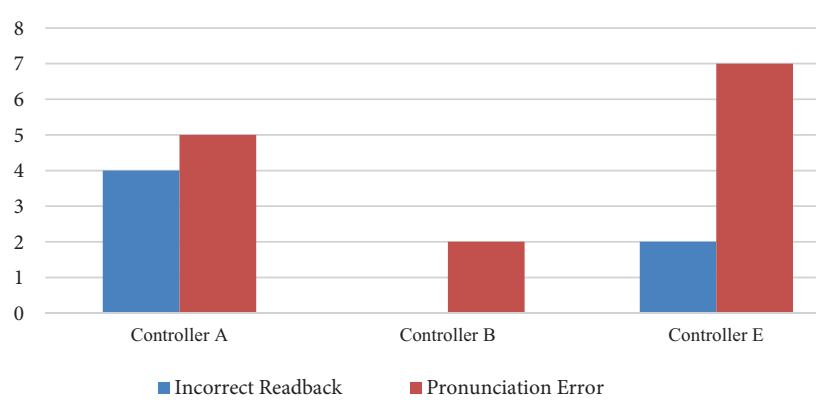

Figure 1. Results of pronunciation error and incorrect readback for Controller E, B and A 
Present results indicate that pronunciation errors made by the controller will affect the clarity of the instruction transmitted by the controllers. In pilot-controller communication, instructions with pronunciation error are prone to be deciphered differently by the hearer, instead of what the speaker intended. The instructions made by the controller are crucial in determining the outcome of the conversations. Therefore, the controller should pronounce every single word clearly with an appropriate speech rate to avoid ambiguity or vagueness in communication.

\subsection{Controller pronunciation and familiarity}

When comparing the error frequencies between Controller $\mathrm{E}$ and Controller B, the result reveals that pronunciation errors have little effect on instructions. However, given that all participants were non-native speakers and shared the same native language, this made them familiar with each other's pronunciation. Moreover, the instructors instructing the simulation training were also non-native speakers and spent months with the controllers at the simulator training center. This may be the factor that affects the instructor's assessment of the controller due to prolonged contact with the controllers. As shown in Figure 1, despite Controller E making numerous pronunciation errors, only two incorrect readbacks were recorded. Controller B had zero pronunciation error with two incorrect read-backs, similar to Controller E. The result indicates that the pilots were familiar with the controller's pronunciation and shared the same context with controllers who possess higher levels of understanding as they have similar pronunciation and understanding. Hence, the efficiency of the controller was not affected. However, this is far from real-life communication that involves foreign pilots with different culture and language backgrounds.

\subsection{Type of errors made by the controllers}

In the next section, each type of error affecting the efficiency of the controllers in the pilot-controller communication are discussed qualitatively by using related examples from the collected data. Table 2 presents the rank of errors that occurred in the simulation. For this study, "tower" represents the controllers' transmissions

Table 4. Wrong instruction

\begin{tabular}{|c|l|l|}
\hline Line & Callsign & \multicolumn{1}{|c|}{ Information } \\
\hline (1) & XAX148 & $\begin{array}{l}\text { Xanadu One Four Eight, will join ten miles } \\
\text { final }\end{array}$ \\
\hline (2) & AIC884 & $\begin{array}{l}\text { Indian Air Eight Eight Four, seven thousand } \\
\text { feet cleared for take-off }\end{array}$ \\
\hline (3) & Tower & Indian Air Eight Eight Four \\
\hline (4) & Tower & $\begin{array}{l}\text { Nine Mike November Sierra Alpha cancels } \\
\text { hold, traffic is Airbus Three Four Six tracking } \\
\text { for final runway 27 }\end{array}$ \\
\hline (5) & 9MAVA & $\begin{array}{l}\text { Nine Mike Alpha Victor Alpha, ready for } \\
\text { departure }\end{array}$ \\
\hline (6) & Tower & $\begin{array}{l}\text { Nine Mike Alpha Victor Alpha, line-up } \\
\text { runway 27 }\end{array}$ \\
\hline
\end{tabular}

while aircraft registration or call signs represent pilots' transmissions.

Vague or wrong instructions error ranked as the highest error. This type of error occurs when the controller gives either ambiguous, erroneous, or incomplete instruction that causes difficulties for pilots to comprehend the instruction correctly. Controllers must adhere to standard terminology and phraseology. However, if the situation is deemed to be crucial, the controller believes that switching to non-standard phraseology or language may improve pilot comprehension.

Table 4 illustrates communication between a controller and four different aircrafts: Air Asia X flight XAX 148, Air India flight AIC 884, 9MNSA, and 9MAVA. Flight XAX 148 was instructed to join at 10 miles final runway 27, while flight AIC 884 was given departure clearance. Immediately after delivering the departure clearance, the controller instructed 9MNSA to cancel current holding and give traffic information to the aircraft. Promptly, 9MAVA transmitted that the aircraft is ready for departure.

Line (4) controller was referring to Xanadu One Four Eight when giving out information to Nine Mike November Sierra Alpha. The controller gave the wrong information (Airbus Three Four Six) to the pilot, as the aircraft model is an Airbus Three Four Zero (A340). This particular error occurs during congested traffic, and the controller might not even realize the mistake. Giving wrong information could easily create confusion and miscommunication. The pilot of Nine Mike November Sierra Alpha could be looking at a different aircraft without realizing the error that had occurred. However, the pilot of Nine Mike November Sierra Alpha did not acknowledge the controller since no read-back was given.

Table 5 illustrates the communication between police aircraft flight Papa Oscar Lima 11 Echo and the tower. The controller instructed the pilot to report at Taipan. However, the controller was giving multiple positions for the aircraft.

Line (7) clearance given by the controller was vague, unclear, and confusing. Moreover, the word "confirm" was used unnecessarily. The controller continued with the clearance without waiting for a call sign identification by the aircraft. Furthermore, the controller gave inaccurate reporting point instructions; either "northeast of Taipan" or "north of Taipan". However, in line (8), the pilot readback as the north-west of Taipan because the designated holding point was the north-west of Taipan. The instructions given by controllers during high-density traffic became disarrayed and they seemed to be anxious and uncertain with their ability as the traffic built up.

Table 5. Vague instruction

\begin{tabular}{|c|l|l|}
\hline Line & Callsign & \multicolumn{1}{|c|}{ Information } \\
\hline$(7)$ & Tower & $\begin{array}{l}\text { Police One One Echo, confirm Police One } \\
\text { One Echo, report north east of Taipan, north of } \\
\text { Taipan }\end{array}$ \\
\hline$(8)$ & $\begin{array}{l}\text { POL } \\
11 \mathrm{E}\end{array}$ & $\begin{array}{l}\text { Police One One Echo, affirm, police one one } \\
\text { echo at North West of Taipan }\end{array}$ \\
\hline
\end{tabular}


The findings indicate that vague or wrong instructions led to confusion and miscommunication in pilot-controller communication. Controllers should remain calm and collected at all times, especially during high-density traffic to ensure all instructions are delivered clearly, concisely and adhere to standard phraseology.

Pronunciation error is the second source of error in pilot-controller communication. However, the error rarely creates confusion or misunderstanding for the pilot because of the L2 familiarity between the participants.

Table 6 illustrates the instruction by the controller to an aircraft call sign Nine Mike November Sierra Alpha. The controller instructed the aircraft to go to the northeast of Labu.

In Table 6, the instruction was for 9MNSA, where line (9) (a) was transmitted by the controller, while (9) (b) was believed to be the correct instruction, which is more appropriate and precise than line (9) (a). The instruction will have a different meaning because of a single pronunciation error; should the aircraft not enter east of Labu? The controller might have been influenced by L1 pronunciation, whereby "North" sounded like "Not". The findings suggest that although pronunciation error occurs frequently in conversation, the errors rarely influence the comprehension of the instruction. However, it can be surmised that pronunciation errors do reduce the overall pilot-controller communication performance based on the rise of per turn transmissions.

Table 7 exhibits the communication between the controller and 9MSME with inaccurate read-back by the pilot.

In Table 7 line (11), the pilot read-back the instruction given with an erroneous level, it was one thousand five hundred feet not one thousand feet. The pilot could have misheard the level, or the pilot expected to be cleared at one thousand feet. Although this situation may seem insignificant, it may cause a mishap during the exercise if the pilot proceeds with the wrong level. The controller cleared the pilot at one thousand five hundred feet, possibly due to another aircraft operating at one thousand feet. However, in line (12), the controller failed to acknowledge

Table 6. Pronunciation error

\begin{tabular}{|l|l|l|}
\hline Line & Callsign & \multicolumn{1}{c|}{ Information } \\
\hline (9) & $\begin{array}{l}\text { (a) } \\
\text { Tower }\end{array}$ & $\begin{array}{l}\text { Nine Sierra Alpha track direct to NOT east } \\
\text { of Labu }\end{array}$ \\
\cline { 2 - 3 } & $\begin{array}{l}\text { (b) } \\
\text { Tower }\end{array}$ & $\begin{array}{l}\text { Nine Sierra Alpha track direct to North east } \\
\text { of Labu }\end{array}$ \\
\hline
\end{tabular}

Table 7. Inaccurate read-back

\begin{tabular}{|c|l|l|}
\hline Line & Callsign & \multicolumn{1}{c|}{ Information } \\
\hline (10) & Tower & $\begin{array}{l}\text { Nine Mike Sierra Mike Echo cleared for } \\
\text { circuit and landing, one thousand five } \\
\text { hundred feet, right hand circuit runway 27 }\end{array}$ \\
\hline$(11)$ & 9MSME & $\begin{array}{l}\text { Cleared for circuit and landing, one thousand } \\
\text { feet, right hand circuit runway 27 }\end{array}$ \\
\hline$(12)$ & Tower & $\begin{array}{l}\text { Nine Mike Sierra Mike Echo request person } \\
\text { on board (POB) and fuel endurance }\end{array}$ \\
\hline
\end{tabular}

the error and continued with the next transmission by requesting information on the total person on board and fuel endurance.

Table 8 below is the communication between an Air Asia Airline flight AXM 762 and tower. Tower delivered the flight clearance for AXM 762 as requested.

In Table 8, line (13) clearance was given to AXM762 by the controller. However, the read-back made by the pilot in line (14) was incorrect. The pilot read-back level cleared as flight level 330 not flight level 350, as instructed by the controller (line (14)). The pilot could have misheard the clearance due to workload, which is customary for them as they have a long list of pre-flight checks. In the event of radio failure, a wrong final level can be dangerous since the aircraft is expected to climb to its final level. However, in line (15), the controller rectified the error by repeating the correct final level.

Both instances above exhibit clearances transmitted to an aircraft during start-up procedure. The findings highlight that incorrect read-back can occur during any traffic sequence, whether heavy, moderate, or low. In addition, errors can transpire even in non-complex and brief instructions.

The transmission made by a controller was never acknowledged by the pilot at any time during the communication. This problem often happens during moderate to heavy traffic, but rarely occurs in low traffic conditions.

The table below exhibits the communication between the tower and aircraft with Nine Mike November Sierra Alpha Charlie. The pilot failed to report on the downwind leg position during the circuit and landing exercise.

In Table 9, line (16) presents the controller's instruction to the pilot to report at the downwind leg position. In this context, the pilot failed to acknowledge that the transmission was received. Read-back is critical at a downwind leg position as the runway might be used by multiple aircraft. There were a lot of possibilities as to why the pilot failed to read-back. The pilot might not have heard the controller's instruction, or the pilot was too occupied with the aircraft's technical system, hence had missed the

Table 8. Wronged read-back

\begin{tabular}{|l|l|l|}
\hline Line & Callsign & \multicolumn{1}{|c|}{ Information } \\
\hline$(13)$ & Tower & $\begin{array}{l}\text { Asian Express Seven Six Two cleared } \\
\text { to Bangkok via A464, flight level 350, } \\
\text { squawk 1233 }\end{array}$ \\
\hline$(14)$ & AXM 762 & $\begin{array}{l}\text { Asian Express Seven Six Two, cleared } \\
\text { to Bangkok via A464, flight level 330, } \\
\text { squawk 1233 }\end{array}$ \\
\hline$(15)$ & Tower & $\begin{array}{l}\text { Asian Express Seven Six Two, I said again } \\
\text { flight level 350 }\end{array}$ \\
\hline
\end{tabular}

Table 9. Failure to read-back in circuit

\begin{tabular}{|l|l|l|}
\hline Line & Callsign & \multicolumn{1}{c|}{ Information } \\
\hline$(16)$ & Tower & $\begin{array}{l}\text { Nine Mike November Sierra Alpha Charlie, } \\
\text { report downwind }\end{array}$ \\
\hline$(17)$ & 9MNSA & -no transmission- \\
\hline
\end{tabular}


transmission. An aircraft needs to report the downwind leg position, as stated in Standard Operating Procedure (SOP). Figure 2 presents the downwind leg position. It is a crucial position in which the pilot is either clear for final or instructed to hold due arrival or departure. If the controller is not aware of the aircraft's position, it may cause imminent danger. This situation could lead to a collision on the final approach or during base leg position.

Table 10 demonstrates the communication between the Indian Air IND 884 flight and the tower. Flight IND 884 failed to report when the aircraft passed six thousand feet, as instructed by the controller.

Line (18) shows that the controller instructed the aircraft to report when passing a specific level. The aircraft is leaving the tower control zone and transfer of control will take place on current radio frequency. Failure to do so will cause confusion and imminent danger. When an aircraft leaves a control zone, they need to switch to a different radio frequency, and the pilot will not be aware of the traffic condition on another control zone or control area. There is always a possibility for another aircraft cruising at the same level as the aircraft. Figure 3 illustrates that upon departure, the aircraft will enter the control zone (CTR) and will proceed to the control area (CTA) after passing a certain designated level or distance. The terminal control area (TMA) is an extended space and distance that could accommodate aircraft for departure and landing. The traffic will be more congested as the terminal control area is wider and higher.

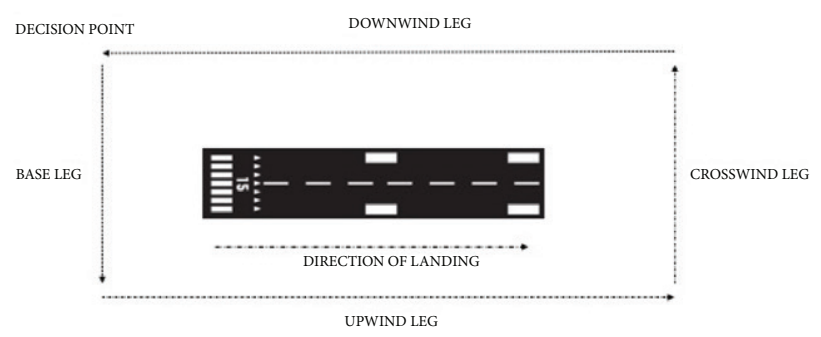

Figure 2. Aerodrome Circuit Pattern

(adapted from Delgado et al., 2009)

Table 10. Failure to read-back during a transfer of control

\begin{tabular}{|l|l|l|}
\hline Line & Callsign & \multicolumn{1}{|c|}{ Information } \\
\hline$(18)$ & Tower & $\begin{array}{l}\text { Indian Air Eight Eight Four, report passing } \\
\text { six thousand }\end{array}$ \\
\hline$(19)$ & 9MNSA & -no transmission- \\
\hline
\end{tabular}

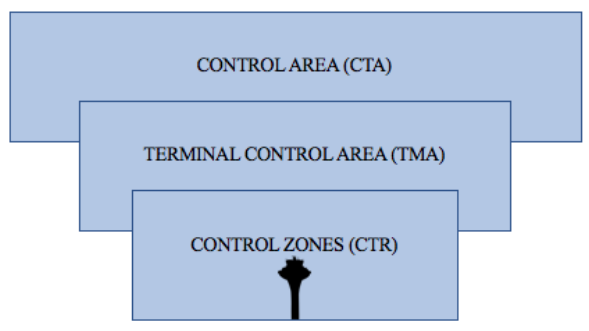

Figure 3. A schematic overview of a generic terminal airspace (adapted from $\mathrm{Li}, 2016$ )
Therefore, it is crucial for every aircraft to acknowledge when leaving the control zone or the control area.

The findings report that pilots need to acknowledge and follow the instructions given by the controllers at all times as every aerodrome or control area is different from one another. Therefore, pilots must anticipate and be prepared with the controller's instructions and clearances. Failure to heed or follow any instruction could lead to a communication error and susceptibility to incidents.

\subsection{Air traffic controller efficiency and language proficiency}

This section discusses the errors that arise due to language proficiency of ab-initio controllers. Although this study focused on clarity and pronunciation, the findings reveal that language proficiency influences the efficiency of the ab-initio controllers. As the instructors implied, despite the practice of altering the emergency injected during the exercise for each controller, it does not change the exercise validity. The present data indicate that although all controllers completed their simulator exercise roughly at the same time, the per-turn communications was greater for controllers with higher communication errors.

Table 11 below demonstrates the communication between police aircraft flight POL 17 and the tower. The controller instructed the aircraft to taxi for stand Victor.

Line (20) shows that the pilot requested to return to the aerodrome (airport). The controller delivered the instruction for Police One Seven to taxi the aircraft to stand Victor five in line (21). However, the controller made an initial mistake by instructing the aircraft to Alpha. On the other hand, a correction was made within the same transmission as the controller realized the mistake. This action had reduced the amount of per-turn in communication.

Table 12 exhibits the communication between Malaysia Airline flight MAS 1 and the tower. The pilot

Table 11. Correction within same transmission

\begin{tabular}{|l|l|l|}
\hline Line & Callsign & \multicolumn{1}{c|}{ Information } \\
\hline$(20)$ & POL 17 & Police One Seven request to return to base \\
\hline$(21)$ & Tower & $\begin{array}{l}\text { Police One Seven return err taxi to Alpha, } \\
\text { correction, taxi to stand Victor five via } \\
\text { taxiway Alpha and Victor }\end{array}$ \\
\hline
\end{tabular}

Table 12. Correction with additional transmission

\begin{tabular}{|l|l|l|}
\hline Line & Callsign & \multicolumn{1}{c|}{ Information } \\
\hline$(22)$ & MAS 1 & Malaysian One ready for taxi \\
\hline$(23)$ & Tower & $\begin{array}{l}\text { Malaysian One taxi to holding point, taxi to } \\
\text { holding point Alpha One via taxiway Sierra, } \\
\text { Victor and Alpha }\end{array}$ \\
\hline$(24)$ & MAS 1 & $\begin{array}{l}\text { Malaysian One taxi to holding point Alpha } \\
\text { One via taxiway Sierra, Victor and Alpha }\end{array}$ \\
\hline$(25)$ & Tower & $\begin{array}{l}\text { Malaysian One hold short at taxiway Victor, } \\
\text { err correction, Malaysia One correction } \\
\text { taxi to holding point Alpha One via Sierra, } \\
\text { Charlie and Alpha }\end{array}$ \\
\hline
\end{tabular}


transmitted that the aircraft was ready for taxi, and the controller immediately instructed the aircraft to taxi to the holding point Alpha using the standard routing. However, the controller then transmitted another clearance to the aircraft to hold at the current position before instructing the aircraft to continue taxi to the holding point Alpha.

Line (23) shows that the controller had instructed the Malaysian One to taxi to the holding point Alpha One through taxiway Sierra, Victor and Alpha. However, due to traffic congestion, the controller immediately gave another instruction to change the taxiway path of the Malaysian One. The correction was done in different transmissions, which increases the per-turn communication.

The findings conclude that the controller's efficiency does not only rely on the English language and aviation English proficiency but also aviation procedure and regulation to improve their competency. However, as the result shows, controllers with a higher level of language proficiency and enhanced knowledge of aviation will perform better in their task as they could adjust to the situation more readily.

\section{Conclusions and suggestions}

The result of this study reveals that communication errors in pilot-controller communication can occur in any part of the conversation in the radiotelephony. Furthermore, there are instances whereby the clarity and pronunciation of the controller's instructions do influence the efficiency of the communication. Situations such as unclear instructions, ambiguous messages, and mispronounced words or phrases often create problematic communication that could reduce the pilots' comprehension during the transmission. However, pronunciation rarely impacts comprehension amongst pilots and controllers who have similar pronunciations and share the same background.

The findings also indicate that controllers should use correct pronunciation to avoid any ambiguity that can reduce the clarity of communication. The data shows that ab-initio controllers will become agitated and uncertain in their instruction during heavy traffic, especially when the situation requires them to construct complex instructions. Although the complexity of instructions is not within the scope of this study, there is also evidence that ab-initio controllers face difficulty in conveying their instruction using proper transmission due to the limited ability to construct sentences in the English language. The controller's proficiency in the English language and aviation English is crucial in maintaining aviation communication safety. The present findings suggest that both pilot and controller should adhere to standard phraseology and be more attentive during high traffic conditions. The current study has given greater insight to the performance of the ab-initio controllers, specifically in non-native speaker settings. The result indicates that it is highly recommended that both ab-initio pilot and controller should achieve a certain level of language proficiency before they could proceed in aviation training (pilot and air traffic controller training), which will require them to wield the language efficiently. The study summarises extensive aviation knowledge that includes various non-routine situations where aviation language training could increase the performance and competency of the ab-initio controllers. Communication adjustment and strategies could be included in aviation communication training for ab-initio pilots and air traffic controllers to improve competency. Furthermore, the concept of minimal English in intercultural communication could benefit the ab-initio controllers and pilots, which may provide a way for people to put their thoughts into words effectively across the language barrier. Additionally, fewer word options force speakers to choose and focus on essential matters rather than contemplating other lexical options. Future research should use a larger number of participants that include ab-initio pilots as it could provide in-depth data for analysis and further exploration of aviation communication training for non-native speakers.

\section{Acknowledgements}

The author would like to thank the Civil Aviation Authority of Malaysia (formerly Department of Civil Aviation Malaysia) for its support and providing data for this research.

\section{References}

Alderson, J. C. (2010). A survey of aviation English tests. Language Testing, 27(1), 51-72.

https://doi.org/10.1177/0265532209347196

Barshi, I. (1997). Effects of linguistic properties and message length on misunderstandings in Aviation Communication [Unpublished Doctoral Dissertation, University of Colorado, Boulder].

Barshi, I., \& Farris, C. (2013). Misunderstandings in ATC communication: Language, cognition, and experimental methodology. Routledge.

Borowska, P. A. (2018). A multilingual speaker in global aviation communication. Journal of Research into Multilingualism, 1(1), 19-28.

Boschen, A. C., \& Jones, R. K. (2004). Aviation language problem: Improving pilot-controller communication. In International Professional Communication Conference, IPCC 2004 Proceedings (pp. 291-299). https://doi.org/10.1109/IPCC.2004.1375313

Burki-Cohen, J. (1995). An analysis of tower (ground) controllerpilot voice communication, DOT/FAA/AR-96/41. US Department of Transportation, Washington, DC.

https://rosap.ntl.bts.gov/view/dot/8641

Campbell-Laird, K. (2004). Aviation English: A review of the language of International Civil Aviation. In International Professional Communication Conference, IPCC 2004 Proceedings (pp. 253-261). https://doi.org/10.1109/IPCC.2004.1375306

Cardosi, K. M., Falzarano, P., \& Han, S. (1998). Pilot-controller communication errors: An analysis of Aviation Safety Reporting System (ASRS) reports. John A Volpe National Transportation Systems Center, Cambridge, MA.

Cookson, S. (2009). Zagreb and Tenerife: Airline accidents involving linguistic factors. Australian Review of Applied Linguistics, 32(3), 22.1-22.14. https://doi.org/10.2104/aral0922 
Delgado, L., Prats, X., Ferraz, C., Royo, P., \& Pastor, E. (2009). An Assessment for UAS Depart and Approach Operations. In 9th AIAA Aviation Technology, Integration, and Operations Conference (ATIO), 6922. American Institute of Aeronautics and Astronautics. https://doi.org/10.2514/6.2009-6922

Drury, C. G., \& Ma, J. (2002). Language error analysis: Report on literature of aviation language errors and analysis of error databases. https://citeseerx.ist.psu.edu/viewdoc/download?do $\mathrm{i}=10.1 \cdot 1.132 .382$ \&rep=rep $1 \&$ type $=$ pdf

Douglas, D. (2014). Nobody seems to speak English here today: Enhancing assessment and training in aviation English. Iranian Journal of Language Teaching Research, 2(2), 1-12. https://eric.ed.gov/?id=EJ1127407

Estival, D., \& Molesworth, B. (2012). Radio miscommunication: EL2 pilots in the Australian general aviation environment. Linguistics and the Human Sciences, 5(3), 351-379. https://doi.org/10.1558/lhs.v5i3.351

Hamzah, H., \& Wong, F. F. (2018). Miscommunication in pilotcontroller interaction. $3 L$ The Southeast Asian Journal of English Language Studies, 24(4), 199-213. https://doi.org/10.17576/3L-2018-2404-15

Hazrati, A. (2015). Intercultural communication and discourse analysis: the case of aviation English. Procedia - Social and Behavioural Sciences, 192, 244-251. https://doi.org/10.1016/j.sbspro.2015.06.035

Howard, J. W. (2008). Tower, am I cleared to land?: Problematic communication in aviation discourse. Human Communication Research, 34(3), 370-391. https://doi.org/10.1111/j.1468-2958.2008.00325.x

Howarth, P. (1998). Phraseology and second language proficiency. Applied Linguistics, 19(1), 24-44. https://doi.org/10.1093/applin/19.1.24

International Civil Aviation Organization (ICAO). (2001). International Standards and Recommended Practices. In Annex 1 to the Convention on International Civil Aviation (11 $1^{\text {th }} \mathrm{ed}$., July 2001). Personnel Licensing.
Jenkins, J. (2000). The phonology of English as an international language. Oxford University Press.

Jones, R. K. (2003). Miscommunication between pilots and air traffic control. Language Problems \& Language Planning, 27(3), 233-248. https://doi.org/10.1075/lplp.27.3.03jon

Kim, H., \& Elder, C. (2009). Understanding aviation English as a lingua franca: Perceptions of Korean aviation personnel. Australian Review of Applied Linguistics, 32(3), 23.1-23.17. https://doi.org/10.2104/aral0923

Li, S. (2016). Air traffic performance improvement of congested terminal airspace with genetic algorithm based optimization [Master thesis, Delft University of Technology, Netherlands]. https://repository.tudelft.nl/islandora/object/ uuid\%3A658ee364-8eb2-4afd-a73c-330071c7f8f6

Mitsutomi, M., \& O’Brien, K. (2003). The critical components of aviation English. International Journal of Applied Aviation Studies, 3(2), 117-129.

Molesworth, B. R. C., \& Estival, D. (2015). Miscommunication in general aviation: The influence of external factors on communication errors. Safety Science, 73, 73-79. https://doi.org/10.1016/j.ssci.2014.11.004

Morrow, D., Lee, A., \& Rodvold, M. (1993). Analysis of problems in routine controller-pilot communication. The International Journal of Aviation Psychology, 3(4), 285-302. https://doi.org/10.1207/s15327108ijap0304_3

Tajima, A. (2004). Fatal miscommunication: English in aviation safety. World Englishes, 23(3), 451-470.

https://doi.org/10.1111/j.0883-2919.2004.00368.x

Trippe, J. (2019). Aviation English listening and repeating task for native English speaker and non-native English speaker pilots. In $20^{\text {th }}$ International Symposium on Aviation Psychology (ISAP 2019) (pp. 235-240). http://resolver.tudelft.nl/ uuid:61cc6928-84ff-4cf7-b0ff-7770185187c7 